\title{
Linguagem e interação na comunicação entre ouvidoria interna e funcionários
}

\author{
Language and interaction in the communieation \\ between the internal listener and the employees
}

Lenguaje e interacción en la comunicación
entre la defensoría interna y los empleados

\section{Asdrúbal Borges Formiga Sobrinho}

- Doutor em Psicologia pela Universidade de Brasília (UnB).

- Mestre em Comunicação Social pela UnB

- Graduado em Comunicação Social, com habilitação em Publicidade e Propaganda, pela UnB

- Professor adjunto do Curso de Comunicação Social da UnB

- Foi professor e assessor pedagógico do Curso de Comunicação Social da Universidade Católica de Brasília (2001-2009)

- Organizador do livro Personagens da propaganda brasileira - Vol. 1.

- asdru_bal@uol.com.br

\section{Rosana Nantes Pavarino}

- Doutoranda em Comunicação na Universidade de Brasília (UnB)

- Mestre em Comunicação pela UnB

- Graduada em Comunicação pela UnB

- Professora do Curso de Comunicação Social da Universidade Católica de Brasília (UCB)

- Professora do Curso de Pós-Graduação em Gestão da Comunicação das Organizações, na Fundação Universa

-rosana.pavarino@gmail.com; ronantes@ucb.br 
Resumo

Este artigo trata do contexto de significação num processo de comunicação que envolve uma ouvidoria interna. Nossa interpretação partiu das peculiaridades da ouvidoria enquanto interlocutora, baseada no relato de um caso e tendo como fundamentação a teoria das representações sociais e a semiótica da cultura. Os resultados foram obtidos com articulação entre linguagem, significação e práticas sociais, por meio da conversa(ção) ou de outras interações realizadas pela ouvidoria, cuja atuação se baseia em normas e valores integrantes da cultura organizacional da instituição.

PALAVRAS-CHAVE: LINGUAGEM • OUVIDORIA INTERNA • REPRESENTAÇÕES SOCIAIS • INTERAÇÃO • CULTURA ORGANIZACIONAL

\section{Abstract}

This article deals with the context of meaning in a process of communication that involves internal ombudsmanship and listening services. Our interpretation originated in the peculiarities of the ombudsman and listener's dialogue, based on a case report, and having the theory of social representation and cultural semiotics as its foundation. The results were obtained from articulation between language, meanings and social practices, through conversation or other interactions conducted by the ombudsman or listener, whose actions are based on standards and values that are constituent parts of the institution's organizational culture.

KEYWORDS: LANGUAGE • INTERNAL OMBUDSMAN • SOCIAL REPRESENTATIONS • INTERACTION • ORGANIZATIONAL CULTURE

\section{Resumen}

Este artículo trata del contexto de significación en un proceso de comunicación que incluye a una defensoría interna. Nuestra interpretación partió de las peculiaridades de la defensoría como interlocutora, basada en el relato de un caso y teniendo como fundamento la teoría de las representaciones sociales y la semiótica de la cultura. Los resultados se obtuvieron a través de la articulación entre el lenguaje, el significado y las prácticas sociales, por medio de la conversación o de otras interacciones realizadas por la defensoría, cuya actuación se basa en normas y valores integrantes de la cultura organizacional de la institución.

PALABRAS CLAVE: LENGUAJE • DEFENSORÍA INTERNA • REPRESENTACIONES SOCIALES • INTERACCIÓN • CULTURA ORGANIZACIONAL 
A proposta deste artigo é tratar do contexto de trocas linguísticas no âmbito de uma ouvidoria, dando continuidade e aplicação à abordagem teórica de reflexões realizadas em um ensaio sobre a publicidade (FORMIGA SOBRINHO, 2007). Para isso, baseamo-nos na distinção entre língua e fala realizada por Saussure (1974) e fundamentada no caráter cultural da língua e social da fala. É neste que verificamos a validação daquele, considerando regras, normas e valores envolvidos na comunicação entre funcionários de uma instituição, materializada por falas e ações de ouvidores internos.

Por um lado e num momento inicial, o procedimento vai ao encontro da crítica de Giddens (1996) ao estruturalismo, ao propor o isolamento entre fala e contexto social, neste caso o ambiente de trabalho; e, por outro, foi realizado em razão de não ser mesmo possível apreender completamente o contexto original da interação entre os falantes, mas apenas de se considerarem características contextuais como a trajetória do demandante e do acusado. A contextualização envolve, por exemplo, posições hierárquicas e o histórico do comportamento institucional dos envolvidos no caso estudado, apontando subjetividades - capazes de gerar ruídos no processo comunicativo -, a serem verificadas na discussão dos dados fornecidos pela ouvidoria da qual tratamos.

A abordagem proposta deve-se ao fato de o código possibilitar a comunicação e constituir uma de suas principais bases, pois "comunicação é parte do estudo das representações, porque as representações são geradas nesse processo de comunicação e depois, claro, são expressas através da linguagem" (MOSCOVICI, 2003, p. 373). Há, portanto, uma dependência de códigos ou de signos, bem como da ação dos sujeitos envolvidos com a linguagem, para a existência de representações, e a mediação de uma interação entre esses polos - o ouvidor e outro funcionário da instituição - conduzirá nossa discussão.

Partimos do princípio de que os dois polos são interdependentes, pois, de um lado, existe uma ação mental sobre os próprios signos, enquanto pensamentos. De outro, existe a história e a construção social da linguagem, as quais, embora nem sempre permitam a descoberta da origem de um significado, permitem tratarmos a linguagem - e não apenas a língua, seu material bruto - como um sistema de representações sociais. Para tanto, baseamo-nos no seguinte pressuposto:

A linguagem, excluída da esfera da realidade material, re-emerge da esfera da realidade histórica e convencional; e, se ela perdeu sua relação com a teoria, ela conserva sua relação com a representação, que é tudo o que ela deixou (MOSCOVICI, 2003, p. 47).

Entretanto, não consideramos a representação o único legado deixado pela linguagem, mas um dos principais, já que os processos de interação entre sujeitos envolvidos na negociação de significados são a base de nossa reflexão sobre a atuação da ouvidoria. Tal espaço de comunicação, mesmo envol- 
vendo novas mídias e tecnologias, confere importância a uma modalidade remota de interação linguística: a conversação cotidiana. Esta cria, mantém ou reforça laços harmônicos ou tensos entre pessoas ou, em palavras de Moscovici (2003, p. 51), "encoraja relações sociais". O autor continua suas considerações sobre a ação afirmando que,

em longo prazo, a conversação (os discursos) cria nós de estabilidade e recorrência, uma base comum de significância entre seus praticantes. As regras dessa arte mantêm todo um complexo de ambiguidades e convenções, sem o qual a vida social não poderia existir. Elas capacitam as pessoas a compartilharem um estoque implícito de imagens e ideias que são consideradas certas e mutuamente aceitas. O pensar é feito em voz alta. Ele se torna uma atividade ruidosa, pública, que satisfaz a necessidade de comunicação e com isso mantém e consolida o grupo, enquanto comunica a característica que cada membro exige dele (MOSCOVICI, 2003, p. 51).

A estabilidade à qual o autor se refere relaciona-se com a busca de conforto psicossociológico, pois a conversação tende a manter o status quo. Porém, sabemos que mudanças acontecem, ainda que, comumente, demorem ou possam ser rápidas quando decorrentes de rupturas, por exemplo. As referidas regras para a vida social, por sua vez, podem ser um produto da linguagem ou mesmo produzi-la, já que a linguagem é uma forma de organizar o pensamento de cada um e sistematizar a comunicação entre dois ou mais indivíduos, no sentido de conferir às mensagens uma estrutura compreensível, organizada por códigos convencionais.

Em princípio, supomos que os envolvidos no processo comunicativo realizado pela ouvidoria, por partilharem o código que estrutura a linguagem e a cultura organizacional, tendem a constituir um grupo em torno da partilha de valores e significados diversos. E, como a agregação é uma necessidade elementar dos indivíduos, a tendência da comunicação - baseada na linguagem e nas representações por ela possibilitadas - é preservar valores e significados, em detrimento da união do grupo ou - no contexto do qual tratamos - do bem-estar da instituição. Entretanto, é preciso conferir relevância a fatores contextuais e subjetividades de quem elabora ou transmite uma mensagem, considerada "a informação que surge num determinado texto" (LOTMAN, 1978 , p. 45). Cabe lembrar que texto, na concepção de Lotman, são as comunicações realizadas por estruturas de uma determinada linguagem; e que a nova informação surgida em cada texto e resultante de processos de interpretação condicionados pela trajetória dos leitores pode ser determinante também de ruídos na comunicação.

Portanto, partimos do pressuposto de que, da mesma forma que os funcionários buscam estabilidade ou conforto para si, a organização, sendo por eles composta e tendo-os atuando em conjunto, também busca manter uma coesão potencialmente geradora ou mantenedora de um bom ambiente de trabalho. 
Tal meta pode ser atingida apenas com base no entendimento mútuo e, consequentemente, na partilha de códigos e valores entre os funcionários, sendo a atuação da ouvidoria fundamental para estabelecimento dessas circunstâncias.

Diante desse contexto, nosso objetivo é investigar como ocorrem os processos de significação em interações entre os funcionários e a ouvidoria de uma instituição. O procedimento parte da apresentação das peculiaridades de uma ouvidoria, destacando-se sua importância como interlocutora, por meio de um estudo de caso. A etapa seguinte é a discussão da atuação da ouvidoria, com base no relato do ouvidor e nos discursos apresentados e fundamentada na articulação entre linguagem, significação e práticas sociais, por meio da conversa(ção) ou das interações realizadas pela ouvidoria. Essa discussão tem como base teórica a teoria da representações sociais, pois uma das perspectivas de estudo das representações sociais apresentadas por Denise Denise Jodelet (1984, apud SÁ, 1998, p. 63) se refere "à representação como forma de discurso e faz decorrer suas características da prática discursiva de sujeitos socialmente situados, [...] da finalidade de seus discursos". Uma outra perspectiva seria "a prática social do sujeito [que] produz uma representação que reflete as normas institucionais que decorrem de sua posição ou as ideologias ligadas ao lugar que ocupa”.

\section{POR DENTRO DE UMA OUVIDORIA}

A ouvidoria da instituição pesquisada funciona há sete anos. Seu público-alvo é formado por funcionários, estagiários e adolescentes trabalhadores - menores carentes ligados a instituições de ensino que a ela se vinculam. Os meios mais utilizados para dialogar com o público são, em ordem decrescente de relevância, internet, telefone, intranet, fax e contato presencial.

Segundo o ouvidor que concedeu entrevistas e forneceu material para análise, $90 \%$ dos casos são imediatamente encaminhados, mas não necessariamente resolvidos; e, dependendo do tipo de demanda, é possível orientar na hora. Os 10\% restantes, principalmente quando envolvem níveis hierárquicos superiores, são mais difíceis de encaminhar, pois dependem de um espaço de interlocução ainda em construção. Os casos mais complexos, que precisam de estudo aprofundado, são registrados em outro sistema, com o uso do programa de computador Access e a geração de uma pasta física e uma virtual. Entre os funcionários da instituição, há uma expectativa de resolução do problema pela ouvidoria, quando o papel desta é mais de mediação, por trabalhar apenas com processos de gestão de pessoas e responsabilidade socioambiental (RSA) e gerenciar conflitos.

Há, portanto, um cunho moral na atuação da ouvidoria diante da ética e da conduta profissional. Os temas mais recorrentes com os quais ela lida dizem respeito a reclamações de funcionários sobre superiores, envolvendo denúncias de assédio moral. Quando estas ocorrem, a ouvidoria interna estuda e 
- dependendo do caso - apura a vida - idade, gênero, etnia, comportamento, família, trajetória etc. - do demandante e do denunciado; a história da sucursal; e o que realmente ocorreu. Tal cuidado é importante porque uma simples chamada de atenção do chefe pode virar objeto de denúncia de assédio moral. Além do mais, trechos de falas como os seguintes podem comumente integrar acusações graves, na concepção dos funcionários que procuram a ouvidoria: "O chefe não me ouve, não está aberto ao diálogo"; "Preciso chegar mais tarde porque moro em outra cidade e meu chefe não entende"; "Preciso sair mais cedo porque estudo e meu chefe não aceita"; "O chefe me coloca para fazer serviços que não me cabem"; etc.

O procedimento seguinte de atuação da ouvidoria é elaborar uma estratégia de abordagem que não exponha os envolvidos. Por exemplo, quando telefona para o chefe de algum departamento, o ouvidor afirma ter conversado com diversos funcionários e ter confirmado determinada conduta, como insultar colegas; pede para o superior daquele departamento corrigir sua conduta; e liga para o funcionário que reclamou, explicando o encaminhamento do processo. Há casosnos quais, após comunicado da ouvidoria sobre muitas reclamações referentes a determinado gestor, um superior atua na transferência do mesmo para outra sucursal. A ouvidoria continua acompanhando e procurando saber se o funcionário já foi transferido para outra sucursal e se o ambiente daquela unidade que apresentava muita reclamação melhorou.

Para um acompanhamento sistemático da avaliação de sua atuação, no início de cada semestre, a ouvidoria costumava fazer uma pesquisa com todos os que a procuraram no semestre anterior, para saber a maneira como julgaram o serviço. Atualmente, a pesquisa é feita com todos os funcionários da instituição e coordenada por uma empresa externa. A proposta é levantar indicadores para depois perguntar se o funcionário recomendaria a ouvidoria, pois, mesmo não tendo a solicitação atendida, é importante saber se ele valoriza e confere credibilidade ao departamento.

Os resultados são importantes para a atuação da instituição como um todo, já que os funcionários serão disseminadores da própria satisfação também externamente. E, como a instituição é hierarquizada, a ouvidoria chega a ser representada como o único canal ao qual os funcionários podem recorrer, pois ela entra na estrutura de poder de forma transversal e busca demonstrar que a instituição quer ouvir e os funcionários têm a quem recorrer.

Por outro lado, a atuação da ouvidoria é fundamental na definição de políticas de gestão de pessoas, como diante de processos de ascensão profissional capazes de discriminar mulheres e de responsabilidade socioambiental. Ela atua na sugestão de mudanças que podem contribuir para a satisfação dos funcionários e, possivelmente, a coesão ou o estabelecimento de laços - ainda que institucionais - entre eles. 
Na seção seguinte, de forma descritiva, trazemos um caso fornecido pela ouvidoria estudada, para depois discutirmos a situação, com base no levantamento teórico apresentado.

\section{MÚLTIPLAS FALAS}

Procurando demonstrar modos de atuação da uma ouvidoria diante de problemas apontados pela fala de funcionários, apresentamos o caso com o qual trabalhamos, fornecido pela instituição pesquisada. Tal caso teve início no dia 13 de fevereiro e encerramento no dia 25 de março de 2009.

O demandante relatou, via telefone, que se sentiu ofendido pelo tratamento recebido de sua chefe imediata. Disse que ela o chamou de traíra, após ouvir de clientes que funcionários da sucursal estão trabalhando contra ela. Disse também que alguns funcionários receberam nota técnica com cobrança de metas e ameaças de redução do quadro da dependência. Citou a existência de dois funcionários afastados por licença-saúde, devido a problemas de gestão e perseguição. O demandante já havia até mesmo conversado com o departamento regional de gestão de pessoas sobre vagas em outras sucursais. Pediu ajuda e sigilo de seu nome.

A ouvidoria ligou para o departamento regional de gestão de pessoas. Ligou também para a sucursal, para falar com a responsável pela comunicação e pelo apoio à gestão. A funcionária que atendeu informou que havia um número $\mathrm{X}$ de funcionários em licença-saúde e explicou caso a caso; esclareceu que a licença-saúde da funcionária A era devido a lesão por esforço repetitivo (LER); a do funcionário $\mathrm{B}$ fora motivada por uma nomeação que o deixou insatisfeito; e a do funcionário $C$ devia-se a um acidente de automóvel. Sobre este último demandante informou que estava em licença-saúde, mas não mais vinculado à dependência, tendo afirmado também que a administração instaurou inquérito administrativo contra ele, o qual alegou problemas psicológicos e entrou em licença-saúde. Após a ouvidoria comentar a situação ruim da sucursal, ela esclareceu que houve perda de uma grande organização, em maio de 2008, sem que o orçamento da dependência fosse revisto pela central. De acordo com ela, não haveria risco de diminuição do quadro da dependência e os funcionários estariam mais motivados atualmente.

A ouvidoria, tendo em vista a solicitação de sigilo, retornou ao demandante, discorrendo sobre o papel da ouvidoria interna e sobre a limitação nesse caso. Ele agradeceu pela ligação e autorizou o contato com a gestora. Entretanto, antes dela, a ouvidoria procurou por outros dois funcionários. A funcionária E informou que a gestora da sucursal assumiu o cargo de forma meio "atropelada", teve um embate com membros da central em relação às metas, devido principalmente à perda de uma grande organização. $\mathrm{O}$ funcionário $\mathrm{F}, \mathrm{da}$ central, disse que o clima da sucursal está melhor, mas relatou autoritarismo na forma como ela cobraria as metas. 
Com base em falas de funcionários que ocupavam cargos similares ao da gestora, a ouvidoria pôde concluir que havia uma cobrança excessiva da central em relação às metas da sucursal por ela conduzida e que, com a mudança de chefia, o relacionamento entre a gestora e a central melhorou, contribuindo também para melhoria no ambiente da sucursal. Já no que diz respeito à ameaça de redução do quadro de funcionários, a ouvidoria procurou pela própria gestora, que negou a informação e indicou a existência de um boato, um exagero.

Mesmo já tendo indicativos resultantes da consulta a diferentes funcionários, a ouvidoria procurou pela gestora, que considerou questionáveis os motivos dos funcionários para afastamento por licença-saúde, com exceção do que tinha lesão por esforço repetitivo (LER). No caso do demandante, ela esclareceu que o processo de descomissionamento foi transparente e justo, tendo sido homologado pelo próprio departamento regional de gestão de pessoas. A gestora acrescentou às dificuldades financeiras da sucursal a própria crise mundial, que refletiu negativamente nas empresas da região cujas operações eram em dólar e ocasionou muita inadimplência. Mesmo assim, ela admitiu ter tomado atitudes centralizadas para minimizar o problema e ter exagerado na cobrança aos funcionários, o que desgastou seu relacionamento na dependência e, mesmo diante de melhoras no ambiente e nos resultados, a motivou a buscar vaga em outra sucursal.

Posteriormente, mas ainda durante o processo em questão, a ouvidoria descobriu adicionalmente que: a administração havia impedido o acesso de responsáveis pelo atendimento a alguns aplicativos e isso gerou uma insatisfação que refletiria negativamente no funcionamento da sucursal; e que o marido da gestora havia falecido, após um ataque fulminante do coração. Isso demonstra que havia informações que os funcionários desconheciam e foram obtidas pela ouvidoria.

Nesse exemplo, observamos um importante aspecto de atuação da ouvidoria, que abordou a acusada após apurar o assunto com diferentes fontes. Ao lidar com denúncias dessa forma, o ouvidor buscou diferentes interpretações das falas, procurando se colocar na posição de cada um dos interlocutores e também ouvir outros para saber, por exemplo, o que realmente um chefe quis dizer ou o que levou um funcionário a compreender o discurso de uma maneira ou de outra.

O processo exemplifica como cada texto, em forma de fala, pode dar diferentes informações para diferentes leitores ou mesmo para um único leitor, em diferentes contextos (LOTMAN, 1978). Demonstra também o fato de o ouvidor não poder se basear apenas nem um primeiro relato e ter procurado conduzir a ouvidoria como uma ferramenta fundamental também para a comunicação entre a instituição e a gestora, que, ao ser acionada, pôde refletir sobre sua linguagem e conduta e avaliar sua gestão. 
Na seção seguinte, discutiremos o caso descrito, considerando a linguagem e as estratégias da ouvidoria para validação ou não de situações apontadas pelo discurso do demandante.

\section{DISCUSSÃO}

Como nosso propósito é investigar características contextuais, os processos de significação envolvidos nas interações entre ouvidor e funcionários da instituição são a base de nossa reflexão sobre a ouvidoria pesquisada. O poder representacional confere à modalidade de comunicação realizada pela ouvidoria grande importância na construção do que conhecemos como realidade. A articulação entre linguagem, significação e práticas sociais, por meio da conversa(ção) ou das interações realizadas pela ouvidoria, demonstra o caráter cultural do fenômeno. Isso porque

A importância dos objetos culturais e informacionais reside no fato de eles introduzirem novas mediações entre cultura, língua e comunicação. Na conversa, o agente e o cenário constituem os meios graças aos quais a cultura se liga à comunicação. Em contextos de ação prática, a comunicação por intermédio da conversa sempre tem de ser "trabalhada" pelos participantes, embora muito desse "trabalho" seja feito rotineiramente, como parte do processo de monitoração reflexiva na monitoração prática. Os objetos culturais rompem essa simetria. Uma vez que a língua "veiculada" por objetos culturais já não é conversa, ela perde a saturação nas propriedades referenciais que o uso linguístico possui nos contextos da ação diária. Como traço visível ou recuperável, separado da imediaticidade dos contextos de conversa, o significante assume importância peculiar (GIDDENS, 1996, p. 311).

No exemplo apresentado, podemos observar a monitoração reflexiva enquanto busca de significações ou de propriedades referenciais para sustento da acusação - produto da monitoração prática - de uma gestora, realizada por um funcionário. Entretanto, se conteúdos veiculados por objetos culturais como a ouvidoria perdem o caráter de conversa, por veicularem a língua e a própria conversa, a fala cotidiana não é tão natural quanto parece. Nesse sentido, mesmo ao dizer que "a fala 'personaliza' a língua vinculando-a aos pensamentos do falante", Giddens (1996, p. 292) a posiciona como elemento cultural, pois uma fala tida como particular é produzida em processos de interação com outras falas e outros elementos da cultura. Esta "pressupõe sistemas de signos cuja organização reproduz comportamentos distintos daqueles considerados naturais que são, assim, culturalizados por algum tipo de codificação” (MACHADO, 2003, p. 39).

Portanto, a comunicação realizada pela ouvidoria da instituição tem um papel determinante na ressignificação das falas e, consequentemente, das condutas de seus funcionários, sendo a modificação resultante de novas interações lin- 
guísticas ou conversas, assim como de reflexões capazes de eliminar os ruídos decorrentes de subjetividades. E, como assim percebemos o fenômeno da fala, ela também se torna uma modalidade de representação, no âmbito da ouvidoria, enquanto expressão não apenas de um único falante em um único contexto espaçotemporal, mas de toda uma construção histórico-social que regula a ação - não apenas de fala - desse falante e de outros.

O caráter regulatório também vai ao encontro do conceito de cultura da semiótica de vertente russa, considerando que para esta

não bastava admitir a cultura como conjugação de sistemas de signos; era preciso compreender a dinâmica que regulava seu funcionamento dentro de uma certa ordem. Para isso, seria fundamental pensar os sistemas como linguagem - um sistema codificado por algum tipo de signo (MACHADO, 2003, p. 47).

Nesse âmbito, observamos o funcionamento da ouvidoria como agente de uma determinada cultura organizacional cujo cunho moral procura estabelecer normas e valores padrões, mas encontra limites e potenciais de negociação em culturas particulares, ou seja, nas subjetividades de cada funcionário envolvido e - paralelamente - dos contextos de interação entre funcionários, dentro da instituição. Esta, pelo menos em um plano ideal, procura manter a estabilidade e o conforto psicossocial de seus funcionários, tendo em vista também os reflexos em seu desempenho. Tal processo, embora não se restrinja a manifestações de caráter linguístico, nelas começa e termina, pois a interpretação das mesmas caracteriza o que Lotman (1978) chama de limite dos textos; e envolve investigação do potencial representacional de determinados signos nesse caso, integrantes de falas - e, a partir de interpretações, pode resultar em ações capazes de ultrapassar o âmbito da conversação.

Cabe lembrar que esse caráter representacional, possibilitado pela ação do signo - paralela à ação do sujeito e também dela resultante - e dependente de contextos sócio-históricos, não deve ser confundido com o meramente ficcional, no sentido de tentar deslocar o conteúdo da linguagem de uma referência tida como concreta, enquanto próxima do contexto espaçotemporal da conversação cotidiana, por exemplo.

Outro paralelo funcional entre o conteúdo da conversa realizada por meio da ouvidoria e o da conversação está no fato de o primeiro também tentar coordenar a ação humana pela forma como representa o tempo e o espaço do receptor. No exemplo apresentado, buscaram-se elementos relacionados à história de vida do demandante e do acusado, dentro e até mesmo fora da instituição, para se poder tirar alguma conclusão e atuar em favor de melhorias para o conjunto de funcionários. Isso porque o processo também ocorre em sentido inverso, ou seja, as ações e práticas sociais atuam na organização do conteúdo das mensagens enviadas à ouvidoria, também legitimadoras de práticas sociais ou por elas legitimadas. O estabelecimento de normas ou regras 
para a organização da estrutura da linguagem e para a consequente significação, portanto, é tanto de caráter social como cultural.

Para maiores considerações sobre o aspecto representacional de linguagens, devemos estar conscientes de que

essas construções não são fiç̧ões desenfreadas. Não se trata de um vale-tudo, porque elas têm como limite as próprias características dos humanos que as produzem, ou seja, as características sociais e biológicas de pessoas historicamente situadas (SPINK, 2004, p. 29) (grifo da autora).

Isso traz à tona a questão do contexto, que inclui os mais diversos aspectos integrantes da cultura dos indivíduos entre os quais a linguagem circula e gera significados. A circulação ocorre, comumente, em forma de conversação, já que esta constitui importante modalidade de construção e reconstrução do pensamento e das práticas sociais, na visão de Moscovici; e, muitas vezes, pressupõe a mescla dos papéis de produção e interpretação dos atos de fala, lembrada por Giddens (1996). No exemplo, podemos observar a tentativa de ouvidores se colocarem no lugar de cada polo envolvido no processo para tentar compreender e diagnosticar a situação, pois "em contextos de copresença, a produção e a interpretação dos atos de fala tendem a mesclar-se, como parte da natureza serial e solidária da conversação” (GIDDENS, 1996, p. 310).

Entretanto, a conversação não ocorre apenas por meio da fala ou da linguagem verbal, ainda que a fala seja um dos modos mais primitivos e o modo mais elementar de comunicação que possuímos e esteja sempre se atualizando, já que a língua é social e, portanto, viva. Tal aspecto contribui para que a ouvidoria cumpra tarefa semelhante à "conversação" (MOSCOVICI, 1961, p. 99), à medida que participa do cotidiano da sociedade, nos limites de um ambiente de trabalho e nas próprias conversas com os funcionários.

Dessa forma, a conversação pode já ter contribuído, previamente, para a consolidação de valores e significados potencialmente associáveis à instituição, internamente, pois a linguagem tanto precisa permear as conversas ou a conversação, quanto por ela(s) é constituída. Como consequência, pode tornar indivíduos familiarizados com objetos estranhos ou mesmo familiarizados entre si, a partir dos laços criados pelos rearranjos linguísticos da conversação. Se o papel da representação é transformar o insólito em familiar (MOSCOVICI, 1961), a ouvidoria constitui um importante mediador no processo de construção e consolidação da cultura organizacional, por meio da conversa direta com os funcionários.

Em alguns momentos, os conceitos e as considerações apresentados por Spink (2004) podem ser justapostos ou confrontados com outros encontrados na teoria de Moscovici. Podemos destacar o que este último chama de transformar 
o insólito em familiar, no processo de ancoragem e objetivação, que pressupõe "inscrever o objeto em nosso universo, isto é, naturalizá-lo e fornecer-lhe um contexto inteligível, isto é, interpretá-lo” (MOSCOVICI, 1961, p. 65). A ancoragem ocorre até o momento de naturalização, enquanto a objetivação conduz o pensamento à interpretação. Spink (2004, p. 27) prefere tratar do processo inverso ou posterior, por ela chamado de desfamiliarização, enquanto deslocamento de um referente conhecido, rumo à ressignificação, ou seja, a um dos possíveis resultados do processo de interpretação.

A atuação da ouvidoria, no sentido de, por meio de conversas, validar ou invalidar o discurso do demandante, pode levantar dúvidas relacionadas a determinados quesitos da situação abordada. Como exemplo, não se sabe exatamente se, ao sofrer com a pressão de membros da central, a gestora não chegou a semear uma ameaça de redução no quadro da dependência, acreditando ser uma forma de motivar os funcionários a atingir melhores metas. Trata-se de algo possível, uma vez que, além do que já foi mencionado, ela era considerada pouco experiente, por trabalhar na instituição há apenas seis anos. Por outro lado, houve uma busca de compreensão para razões externas que poderiam alterar o comportamento da gestora, como a perda recente do marido.

O procedimento, que envolveu conversação e ações paralelas, possibilitou reconstruir uma representação da gestora, procurando ir além do que havia sido mencionado pelo demandante e também por outros funcionários. Em outras palavras, buscou-se uma desfamiliarização com uma representação e melhorias no ambiente de trabalho, procurando cumprir metas da ouvidoria.

\section{ENTENDIMENTO}

No exemplo interpretado, a ouvidoria parece ter cumprido seus objetivos diante da instituição; e o ouvidor, ao ter desempenhado seu papel de ombudsman, tornou-se um agente intermediário entre a cultura organizacional e as culturas individuais. Isso porque o processo envolveu subjetividades, potencialmente transferíveis para a organização ou dela herdados. Nele pessoas e a própria ouvidoria se inter-relacionaram como textos, dispostos ou destinados a falar a língua da instituição, validar sua cultura organizacional - em princípio, partindo de normas e valores - e trabalhar na construção de um ambiente favorável, agindo em limites entre valores canônicos e inovadores.

Entretanto, o caráter jurídico (IASBECK, 2009) da atuação do ouvidor e da ouvidoria pode ser ambíguo, mesmo ainda não havendo dados suficientes para demonstrar tal ambiguidade, diante da obtenção de exemplos bem-sucedidos e do diálogo apenas com um ouvidor. Esse contexto, portanto, aponta limites no potencial de generalização das informações apresentadas, mas não nos impede de confirmar duas das suposições levantadas no início do artigo. 
A primeira refere-se à dependência de códigos ou signos, paralelamente à ação dos sujeitos envolvidos com a linguagem, para a existência de representações e para a viabilização da interpretação a partir da mediação entre as diferentes partes envolvidas. A segunda refere-se ao paralelismo entre a busca de estabilidade ou conforto mental realizada por funcionários, em função de si próprios, e pela ouvidoria, em função da instituição que busca construir ou manter um bom convívio entre seus funcionários.

Porém, foi negada a suposição referente à possibilidade de os funcionários tenderem a construir um grupo em torno da partilha de valores e significados diversos, por partilharem o código que estrutura a linguagem e a cultura organizacional. Seria uma situação ideal e talvez a meta máxima de uma ouvidoria, mas nem mesmo no caso apresentado como bem-solucionado isso ocorreu. Observamos que tende a ocorrer uma adequação de cada um à circunstância, mas não necessariamente a criação de um espírito de grupo.

\section{CONSIDERAÇÕES FINAIS}

Podemos destacar, dentre as possíveis consequências do trabalho da ouvidoria, a possibilidade de compor uma etapa no aprendizado da compreensão de textos (LOTMAN, 1978) e, portanto, da compreensão da linguagem partilhada por pessoas que representam a instituição. Tal compreensão, entretanto, constitui um efeito ideal, pois a compreensão ou interpretação é um efeito desejado ou previsto por quem fala em nome da instituição. Esse agente tenta conferir à linguagem um caráter ou uma função semelhante à conversação ou mesmo inseri-la em contextos de conversação que tentem apagar as fronteiras entre receptor e mensagem, mas irá encontrar limites principalmente na forma como a mensagem é recebida. Tais limites podem ser materializados em falas características de ruídos. Assim pode concretizar-se o referido processo de ancoragem e objetivação (MOSCOVICI, 1961) e a capacidade comunicativa da ouvidoria amplia-se e diversifica-se, podendo ser adaptada a cada indivíduo, de acordo com a forma como ele se relaciona com a instituição e o contexto social que ele vivencia nela.

Dessa maneira, o laboratório da ouvidoria não somente propõe como consolida algo semelhante ao rompimento do suposto isolamento entre língua e fala, levantado no início deste artigo. Isso porque considera uma série de variáveis para dialogar com seu público e assim caracteriza uma dependência de códigos ou de signos, bem como da ação dos sujeitos envolvidos com a linguagem.

No que diz respeito ao último aspecto, tanto o código deve ser comum entre emissor e receptor, quanto os efeitos da comunicação devem contribuir para o estabelecimento de laços entre as pessoas que passarem a partilhar - ou intensificarem a partilha de - valores, a partir do contato com a ouvidoria. Esta se torna assim capaz de gerar estabilidade e conforto mental para as pessoas 
e a instituição, já que tanto obedece quanto reforça ou reforma regras para formas de se atuar na mesma. A consolidação desse processo - capaz inclusive de gerar novos significados e assim aprimorar os resultados atingidos pela instituição -, tem seu início e seu fim na conversação cotidiana, mãe da comunicação, em geral, e da comunicação realizada pela ouvidoria, em particular.

\section{REFERÊNCIAS}

FORMIGA SOBRINHO, Asdrúbal Borges. Se publicitário vende até a mãe, quem será a mãe da publicidade? In: CONGRESSO BRASILEIRO DE CIÊNCIAS DA COMUNICAÇÃO, XXX, 2007, Santos (SP). Anais... São Paulo: Intercom, 2007. CD-Rom.

GIDDENS, Anthony. Estruturalismo, pós-estruturalismo e a produção da cultura. In: GIDDENS, Anthony; TURNER, Jonathan (Org.). Teoria social hoje. São Paulo: Unesp, 1996. p. 281-319.

IASBECK, Luiz Carlos Assis. Ouvidoria, lugar privilegiado de comunicação organizacional. In: CONGRESSO BRASILEIRO DE CIÊNCIAS DA COMUNICAÇÃO, XXXII 2009, Curitiba (PR). Anais... São Paulo: Intercom, 2009. CD-Rom.

JODELET, Denise. Représentation sociale: phénomènes, concept et théorie. In: MOSCOVICI, Serge (Org.). Psychologie sociale. Paris: PUF, 1984. p. 357-358.

LOTMAN, luri. $A$ estrutura do texto artístico. Lisboa: Editorial Estampa, 1978.

MACHADO, Irene. Escola de semiótica: a experiência de Tártu-Moscou para o estudo da cultura. São Paulo: Ateliê Editorial / Fapesp, 2003.

MOSCOVICI, Serge. 0 fenômeno das representações sociais - Investigações em psicologia social. In: MOSCOVICl, Serge. Representações sociais. 2. ed. São Paulo: Vozes, 2003. p. 29-109.

. A representação social da psicanálise. Rio de Janeiro: Jorge Zahar, 1961.

SÁ, Celso Pereira. A construção do objeto de pesquisa em representações sociais. Rio de Janeiro: Eduerj, 1998.

SAUSSURE, Ferdinand de. Course in general linguistics. Londres: Fontana, 1974.

SPINK, Mary Jane; FREZZA, Rose Mary. Práticas discursivas e produção de sentidos no cotidiano: a perspectiva da psicologia social. In: SPINK, Mary Jane (Org.). Práticas discursivas e produção de sentidos no cotidiano: a perspectiva da psicologia social. São Paulo: Cortez, 2004. p. 17-39.

Recebido em: 18.01.2010 / Aceito em: 24.02.2010 